\title{
IMPLEMENTAÇÃO DA NORMA DE DESEMPENHO NBR 15575:2013: ESTUDO DE CASO EM RECIFE/PE
}

\author{
IMPLEMENTATION OF THE BRAZILIAN PERFORMANCE STANDARD NBR 15575:20: \\ CASE STUDY IN RECIFE/PE
}

\author{
Gabriela Alves Tenório de Morais ${ }^{1}$, Alberto Casado Lordsleem Jr. ${ }^{1}$, Paulo Roberto Pereira \\ Andery $^{2}$
}

\section{RESUMO:}

A dificuldade da indústria da construção civil em implementar a norma de desempenho NBR 15575:2013 é uma realidade que tem marcado o cenário contemporâneo. Diante desse quadro, este trabalho tem por objetivo identificar e avaliar a implementação da NBR 15575:2013 em empresas construtoras e incorporadoras. A pesquisa teve natureza descritiva e a estratégia adotada foi o estudo de casos realizados na cidade de Recife/PE. A metodologia contemplou o levantamento de dados, a descrição e a análise crítica das ações desenvolvidas pelas empresas e o estabelecimento de soluções para a implementação. Identificou-se que as principais ações para implementação foram: realização da análise de riscos do entorno da obra; contratação de novas especialidades de projeto; exigência em contrato do atendimento à NBR 15575:2013; elaboração do Perfil de Desempenho da Edificação e do Plano de Controle Tecnológico; solicitação de compra de materiais por especificação de desempenho; treinamento das equipes de execução, e; revisão dos manuais dos usuários. Diante do exposto, acredita-se que a presente pesquisa contribui para nortear as empresas construtoras e incorporadoras, bem como para auxiliar na implementação de normativas de caráter semelhante à NBR 15575:2013.

PALAVRAS-CHAVE: Norma brasileira de desempenho; Implementação; Método; Empresas construtoras e incorporadoras.

\section{ABSTRACT:}

The difficulties faced by companies in the construction industry to implement the Brazilian Performance Standard NBR 15575:2013 has marked the current scenario. This work aims to identify and evaluate the implementation of NBR 15575:2013. The research was descriptive with the case study as a strategy. The scope involved the city of Recife/Pernambuco. The methodology included data collection, description and critical analysis of the actions developed by the companies and the establishment of solutions. It was identified that the main actions for implementation were: performing the risk analysis of the construction site; hiring of new design specialties; requirement in contract of attendance to NBR 15575:2013; elaboration of the Enterprise Performance Profile and the Technological Control Plan; purchase order of materials by performance specification; training and sensitization of project execution teams, and; revision of the Use, Operation and Maintenance Manual. In view of the above, it is believed that this research contributes to guiding the construction companies and developers, as well as to assist in the implementation of regulations similar to NBR 15575:2013.

KEYWORDS: Brazilian Standard of Performance; Implementation; Method; Construction companies and developers.

How to cite this article:

MORAIS, G.A.T.; LORDSLEEM JR., A.C.; ANDERY, P.R.P. Implementação da norma de desempenho NBR 15575:2013: estudo de caso em Recife/PE. Gestão \& Tecnologia de Projetos. São Carlos, v16, n2, 2021. https://doi.org/10.11606/gtp.v16i2.167683

Fonte de Financiamento: FACEPE

Conflito de Interesse: Declara não haver.

Submetido em: $12 / 02 / 2020$ Aceito em: 25/12/2020 


\section{INTRODUÇÃO}

Ainda que em vigor desde 2013, a implementação da norma de desempenho NBR 15575:2013 (ABNT, 2013) é incipiente em alguns lugares do Brasil, onde observa-se que os níveis de atendimento são baixos e que há despreparo por parte das empresas da indústria em articular ações para atender suas exigências (OKAMOTO; MELHADO, 2014; CRUSIUS, 2015; OKAMOTO, 2015; SARVEZUK; SILVA, 2015; COTTA; ANDERY, 2016; CTE, 2016; MOURA; SANTOS; PINHEIRO, 2016; OTERO; SPOSTO, 2016; SANTOS et al., 2016; COTTA, 2017; ANDERY; BARBOSA, 2018; BELÉM; STARLING; ANDERY, 2018; MEIRA; VASQUE, 2018; MORAIS et al., 2018a; MORAIS et al., 2018b; PRANGE; LYRA; SANTOS, 2018; SANTOS, 2018; SANTOS; SANTOS, 2018b; VIANA et al., 2018).

Em sintonia com as exigências da NBR 15575:2013, o Sistema de Avaliação de Conformidade das Empresas de Serviços e Obras de Construção Civil (SiAC), regimento do Programa Brasileiro de Qualidade e Produtividade do Habitat (PBQP-H) (BRASIL, 2018), passou a exigir o atendimento à normativa (COTTA, 2017). Uma vez que a certificação no SiAC está vinculada à obtenção de financiamentos junto à agentes financeiros da habitação e crédito imobiliário, como a Caixa Econômica Federal, (WEBER; JOPPERT, 2011), o descumprimento da NBR 15575:2013 dificulta a captação de recursos.

Apesar dessas mudanças no contexto de mercado, poucas pesquisas sistematizam como as empresas construtoras e incorporadoras devem organizar suas ações de forma a atender às exigências da NBR 15575:2013 ou criar ferramentas que as auxiliem neste processo (COTTA, 2017; VIANA et al. 2018; SANTOS; SANTOS, 2018a).

Para Andery e Barbosa (2018), a documentação de experiências de implementação da NBR 15575:2013 ainda é limitada, e deve atender a particularidades associadas aos sistemas gerenciais e condições de operação nas quais as empresas estão inseridas (FOLIENTE, 2004).

Diante do exposto, o objetivo deste artigo é identificar e avaliar a implementação da NBR 15575:2013 em empresas construtoras e incorporadoras. A pesquisa tem cerne no contexto brasileiro, tendo em vista as características singulares de organização da indústria da construção bem como da própria norma brasileira de desempenho. Assim, serão priorizados os conhecimentos e as experiências nacionais. Destaca-se que este artigo se baseia em informações disponibilizadas por empresas construtoras e incorporadoras acerca do processo de implementação da NBR 15575:2013, por meio de pesquisa realizada na cidade de Recife, Pernambuco, entre março de 2017 e março de 2019. Além disso, ressalta-se que a pesquisa apresenta os resultados de uma dissertação de mestrado acadêmico fruto de um projeto de pesquisa do Programa de Pós-graduação em Engenharia Civil da Escola Politécnica da Universidade de Pernambuco.

\section{MATERIAIS E MÉTODOS}

Esta pesquisa consistiu-se em uma pesquisa de campo de natureza descritiva (Marconi; Lakatos, 2003) cuja estratégia adotada foi o estudo de múltiplos casos (GIL, 2002). A metodologia empregada no âmbito dos estudos de caso contemplou as etapas descritas na Figura 1. Cabe ressaltar que os dados coletados não pretendem ser conclusivos ou descrever a prática de todo o mercado, porém é possível que apresentem características semelhantes com parcela expressiva das empresas de construção. 


\begin{tabular}{|c|}
\hline Revisão da literatura \\
\hline Definição da amostra \\
\hline Participação no método para implementação da NBR 15575:2013 \\
\hline Elaboração do instrumento operacional: formulários \\
\hline Aplicação dos formulários piloto \\
\hline Adequação dos formulários \\
\hline Realização de entrevistas para aplicação dos formulários \\
\hline Triangulação e análise dos dados coletados \\
\hline
\end{tabular}

Para determinar o panorama das pesquisas acerca do tema objeto de estudo, foi realizada uma revisão sistemática com uso do método PRISMA (GALVÃO; PANSANI; HARRAD, 2015) por meio de uma busca na literatura nacional e internacional indexada nas bases de dados SciELO, Scopus e Materials Science \& Engineering. As palavras-chave utilizadas foram: "norma de desempenho" OR "norma de desempeño" OR "brazilian performance standard" OR "NBR 15575" OR "NBR 15575". A busca incluiu artigos publicados no período de 2013 a 2018 e resultou em 41 artigos que tinham como foco principal a NBR 15575:2013 (Quadro 1), dos quais apenas quatro trazem contribuições à implementação da normativa ao tratar dos reflexos da NBR 15575:2013 no processo de projetos (COSTA; ILHA, 2017; COTTA; ANDERY, 2018), dos impactos decorrentes da NBR 15575:2013 a indústria da construção (SILVA, A. T. et al., 2014) e dos custos oriundos da implementação da norma de desempenho (GARLET et al., 2017). Os resultados da revisão sistemática reforçaram a necessidade do desenvolvimento de pesquisas acerca da implementação da NBR 15575:2013.

Para realização dos estudos de casos foram selecionadas quatro empresas denominadas como empresas A, B, C e D, que participaram de um mesmo processo de capacitação para implementação da norma de desempenho, o qual envolvia um total de 11 empresas construtoras e incorporadoras; e cujos critérios adotados para seleção são apresentados na Figura 2. Destaca-se que das 11 empresas participantes do processo de capacitação, apenas as quatro empresas selecionadas atendiam a todos os critérios apresentados na Figura 2. Destas, a Empresa A foi selecionada para viabilizar o acompanhamento das atividades do processo de capacitação por apresentar maior facilidade de contato e disponibilidade para fornecer informações dentro do conjunto das quatro empresas que aceitaram participar da pesquisa. A participação permitiu entender como estas empresas foram capacitadas no que tange aos conteúdos e ferramentas que as auxiliariam. Cabe destacar que o método objeto de estudo objetivou capacitar as empresas para atender às exigências da NBR 15575:2013 no que diz respeito aos processos de incorporação, projetos, suprimentos, execução de obras e pós-obras e que, por esta razão, estes serão os processos discutidos nesta pesquisa.

Os instrumentos de coleta de dados adotados como fonte de evidências nesta pesquisa foram: observação direta, entrevistas estruturadas, formulários e análise de documentos. Foram elaborados sete formulários, os quais buscavam caracterizar as empresas, os impactos da implementação aos processos de incorporação, projetos, suprimentos, execução de obras e pós-obras e a certificação no SiAC. Por meio destes instrumentos foi possível entender detalhadamente as ações desenvolvidas e as dificuldades vivenciadas para implementar a NBR 15575:2013.
Figura 1. Fluxograma das etapas de desenvolvimento da pesquisa

Fonte: Elaborado pelos autores. 
Quadro 1. Revisão sistemática: artigos selecionados e temas abordados

Fonte: Elaborado pelos autores.

Figura 2. Critérios para definição da amostra

Fonte: Elaborado pelos autores.

\begin{tabular}{|c|c|c|}
\hline Grupo & Tema & Estudo \\
\hline \multirow{9}{*}{$\begin{array}{l}\text { Exigências dos } \\
\text { usuários }\end{array}$} & $\begin{array}{l}\text { Desempenho } \\
\text { Térmico }\end{array}$ & $\begin{array}{l}\text { CHVATAL, 2014; SILVA, A. S et al., 2014; SILVA; GHISI, 2014; } \\
\text { SORGATO et al., 2014; TUBELO; RODRIGUES; GILLOTT, } \\
\text { 2014; SANTOS et al., 2015; TRIANA; LAMBERTS; SASSI, } \\
\text { 2015; ADAMY; ROSA; ROSA, 2016; BOGO, 2016; REUS } \\
\text { NETTO; CZAJKOWSKI, 2016; FERREIRA; SOUZA; ASSIS, } \\
\text { 2017; GARLET et al., 2017; SOARES; SILVA, 2017; MUNIZ- } \\
\text { GÄAL et al., 2018; SILVA et al., 2018; TUBELO et al., 2018; } \\
\text { DALBEM et al., } 2019\end{array}$ \\
\hline & $\begin{array}{l}\text { Desempenho } \\
\text { Acústico }\end{array}$ & $\begin{array}{l}\text { RIBEIRO et al., 2014; SCHVARSTZHAUPT; TUTIKIAN; NUNES, } \\
\text { 2014; OLIVEIRA FILHO; ZANNIN, 2016; GARLET et al., 2017; } \\
\text { PACHECO et al., 2017; SANTANA et al., 2017; TUTIKIAN et } \\
\text { al., 2017; KLIPPEL FILHO et al., 2018; SILVA et al., } 2018\end{array}$ \\
\hline & $\begin{array}{l}\text { Resistência ao } \\
\text { fogo }\end{array}$ & $\begin{array}{c}\text { BOLINA et al., 2015; BOLINA et al., 2017; HENNEMANN et } \\
\text { al., 2017; KLIPPEL FILHO et al., } 2018\end{array}$ \\
\hline & $\begin{array}{l}\text { Durabilidade e } \\
\text { vida útil }\end{array}$ & $\begin{array}{c}\text { OLIVEIRA; FONTENELLE; MITIDIERI FILHO, 2014; BOLINA; } \\
\text { TUTIKIAN, 2016; GARCEZ; ROHDEN; GODOY, 2018; } \\
\text { SENTENA; KAZMIERCZAK; KREIN, } 2018\end{array}$ \\
\hline & $\begin{array}{l}\text { Desempenho } \\
\text { Estrutural }\end{array}$ & $\begin{array}{c}\text { ALVA et al., 2015; MORASSI; SILVA; ORTENZI, 2018; } \\
\text { NOGUEIRA; CALLEJAS; DURANTE, 2018; SILVA; THOMAZ; } \\
\text { OLIVEIRA, } 2018\end{array}$ \\
\hline & Estanqueidade & SILVA; THOMAZ; OLIVEIRA, 2018 \\
\hline & $\begin{array}{c}\text { Desempenho } \\
\text { ambiental }\end{array}$ & MOURA; SANTOS; PINHEIRO, 2016; GIORGI et al., 2018 \\
\hline & Habitabilidade & GIORGI et al., 2018 \\
\hline & $\begin{array}{l}\text { Desempenho } \\
\text { Lumínico }\end{array}$ & GUIDI et al., 2018 \\
\hline \multirow{3}{*}{ Implementação } & Projetos & COSTA; ILHA, 2017; COTTA; ANDERY, 2018 \\
\hline & Impactos & SILVA, A. T. et al., 2014 \\
\hline & Custos & GARLET et al., 2017 \\
\hline
\end{tabular}

Participar do método para implementação da NBR 15.575:2013. investigado na pesquisa

Empresa construtora e/ou incorporadora voltada ao mercado imobiliário residencial

Estar passando pelo processo de certificação ou ser certificado no regimento SiAC do PBQP-H

Facilidade de contato

Disponibilidade para fornecer informações

Os formulários foram aplicados de modo piloto na Empresa A, o que permitiu a verificação da adequação. Após a análise crítica, estes instrumentos foram revisados a fim de reduzir o tempo de realização das entrevistas. As entrevistas foram realizadas de acordo com roteiro preestabelecido e com a utilização, em via impressa, da solicitação de disponibilização de documentos e dos formulários de coleta de dados. 
Entre os documentos analisados destacaram-se padrões e registros dos sistemas de gestão da qualidade, checklists de projetos de arquitetura e engenharia e resultados de ensaios e simulações realizadas pelas empresas. Os dados obtidos foram compilados, triangulados e analisados criticamente de forma a caracterizar e permitir a avaliação da implementação da norma de desempenho.

\section{ESTUDOS DE CASOS: APRESENTAÇÃO E ANÁLISE CRÍTICA}

O Quadro 2 caracteriza as empresas investigadas. Cabe ressaltar que todas as empresas são certificadas no SiAC.

\begin{tabular}{|c|c|c|c|c|c|}
\hline \multicolumn{2}{|c|}{ Características $\quad$ Empresa } & Empresa A & Empresa B & Empresa C & Empresa D \\
\hline \multicolumn{2}{|c|}{ Ramo de Atuação } & $\begin{array}{l}\text { Construção, } \\
\text { incorporação } \\
\text { e imobiliária }\end{array}$ & $\begin{array}{l}\text { Construção, } \\
\text { incorporação } \\
\text { e imobiliária }\end{array}$ & $\begin{array}{l}\text { Construção, } \\
\text { incorporação } \\
\text { e imobiliária }\end{array}$ & $\begin{array}{l}\text { Construção e } \\
\text { incorporação }\end{array}$ \\
\hline \multirow[b]{2}{*}{ Empreendimentos } & Tipologia & $\begin{array}{c}\text { Habitacional, } \\
\text { comercial, } \\
\text { público e } \\
\text { industrial }\end{array}$ & $\begin{array}{l}\text { Habitacional } \\
\text { e comercial }\end{array}$ & $\begin{array}{c}\text { Habitacional, } \\
\text { comercial, } \\
\text { público e } \\
\text { industrial }\end{array}$ & Habitacional \\
\hline & Padrão & Médio a Alto & Médio a Alto & $\begin{array}{l}\text { Habitação de } \\
\text { Interesse } \\
\text { Social, } \\
\text { Econômico, } \\
\text { médio e alto }\end{array}$ & $\begin{array}{c}\text { Habitação de } \\
\text { Interesse } \\
\text { Social }\end{array}$ \\
\hline \multicolumn{2}{|c|}{ № de funcionários } & 250 & 200 & 700 & 300 \\
\hline \multicolumn{2}{|c|}{ Tempo de atuação } & 68 anos & 43 anos & 52 anos & 19 anos \\
\hline \multicolumn{2}{|c|}{ № de obras entregues } & 46 & 50 & $\begin{array}{c}\text { Não } \\
\text { informado }\end{array}$ & 9 \\
\hline \multicolumn{2}{|c|}{ № de obras em execução } & 12 & 2 & 5 & 3 \\
\hline \multicolumn{2}{|c|}{ Certificações } & $\begin{array}{l}\text { ISO 14001; } \\
\text { ISO 18001; } \\
\text { ISO } 9001 \text { e } \\
\text { PBQP-H }\end{array}$ & $\begin{array}{l}\text { ISO } 9001 \text { e } \\
\text { PBQP-H }\end{array}$ & $\begin{array}{l}\text { ISO 14001; } \\
\text { ISO 9001; } \\
\text { OHSAS } \\
18001 \mathrm{e} \\
\text { PBQP-H }\end{array}$ & $\begin{array}{l}\text { ISO } 9000 \text { e } \\
\text { PBQP-H }\end{array}$ \\
\hline \multicolumn{2}{|c|}{ Sistema de Gestão Integrada } & Possui & Possui & Possui & Possui \\
\hline
\end{tabular}

A descrição das atividades de implementação da norma de desempenho desenvolvidas individualmente pelas empresas A, B, C e D é apresentada no Quadro 3. Neste âmbito, a compilação dos dados obtidos no Quadro 3 permitiu identificar que as mudanças mais recorrentes oriundas da implementação da Norma de Desempenho, por processo, citadas pelas empresas foram:

- Processo de Incorporação: (1) elaboração da Planilha de Análise de Riscos, na qual, para a maioria das empresas, os riscos são analisados probabilisticamente; (2) realização do mapeamento acústico do entorno da obra, e; (3) contratação de consultorias para desenvolver análises das condicionantes térmicas e acústicas do entorno.

- Processo de Projetos: (1) contratação de novas especialidades de projetos, a exemplo das disciplinas de térmica, acústica e lumínica; (2) criação e atualização de checklists
Quadro 2. Caracterização das empresas estudadas

Fonte: Elaborado pelos autores. 
de verificação de projetos, tendo em vista a contratação de novas especialidades e as novas exigências decorrentes da Norma de Desempenho. Neste sentido, a Empresa D optou pela criação de um único checklist que compila todas as exigências da Norma de Desempenho; (3) elaboração do Perfil de Desempenho da Edificação (PDE), exigência do regimento SiAC atendida por todas as empresas investigadas; (4) alteração das minutas de contratação de projetistas, as quais passaram a exigir o cumprimento da NBR 15575:2013, o estabelecimento da vida útil de projeto (VUP) e a especificação dos cuidados no uso, operação e manutenção dos empreendimentos; (5) mudança do protocolo de alteração de projeto durante a execução dos empreendimentos com a obrigatoriedade da anuência dos projetistas previamente à realização das modificações em campo, e; (6) maior detalhamento dos memoriais descritivos, os quais passaram a trazer especificações por desempenho e referências às normas técnicas pertinentes.

- Processo de Suprimentos: (1) aumento da quantidade de informações requeridas e fornecidas pelos fabricantes; (2) inserção de especificações de desempenho nas ordens de compra; (3) utilização do Plano de Controle Tecnológico (PCT ) como documento norteador para auxiliar na caracterização do desempenho dos materiais a serem adquiridos; (4) participação do corpo técnico na avaliação da adequação dos suprimentos, quando do recebimento em obra; desenvolvimento de novos instrumentos para auxiliar a compra de materiais. A exemplo do "Criação de caderno de especificação de materiais", desenvolvido pelas Empresas C e D; (5) adequação da qualificação de fornecedores, a qual passou a questionar a capacidade destes agentes em atender à Norma de Desempenho, e; (6) adequação do procedimento operacional de suprimentos, decorrente das mudanças descritas.

- Processo de Execução de Obras: (1) elaboração do Plano de Controle Tecnológico, documento que é exigência do SiAC e traz a compilação dos ensaios que serão realizados durante a execução para verificação do desempenho; (2) realização de treinamentos para sensibilização da mão-de-obra acerca da importância e da mudança de cenário decorrente da Norma de Desempenho, e; (3) maior registro e documentação das inspeções de serviços.

- Processo de Pós-Obras: (1) atualização dos manuais de uso, operação e manutenção, os quais passaram a apresentar prazos de garantia e cuidados no uso, operação e manutenção dos empreendimentos.

Percebe-se do exposto que há um desequilíbrio na quantidade de ações a serem desenvolvidas pelos processos citados, isto porque, processos como o de projetos demanda mais ações, o que é esperado dado que são as características dos projetos governam o desempenho de uma edificação. No entanto, cabe ressaltar que todas as ações elencadas são fundamentais e contribuem preponderantemente para garantia do adequado desempenho das edificações. Em relação às ações desenvolvidas pelas empresas, destacam-se alguns pontos que suscitaram questionamentos e reflexões. 


\begin{tabular}{|c|c|c|c|c|c|}
\hline \multicolumn{2}{|c|}{$\begin{array}{l}\text { EMPRESA } \\
\text { PROCESSO } \\
\end{array}$} & EMPRESA A & EMPRESA B & EMPRESA C & EMPRESA D \\
\hline \multirow{3}{*}{ 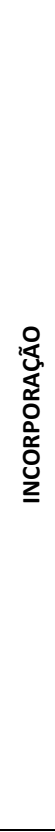 } & Mudanças & $\begin{array}{l}\text { (a) Realização da análise de } \\
\text { riscos; (b) Realização da } \\
\text { análise acústica do entorno da } \\
\text { obra. }\end{array}$ & $\begin{array}{l}\text { (a) Elaboração da } \\
\text { Planilha de Análise } \\
\text { de Riscos; (b) } \\
\text { Realização da } \\
\text { análise acústica do } \\
\text { entorno da obra. }\end{array}$ & $\begin{array}{l}\text { (a) Realização da } \\
\text { análise de riscos } \\
\text { com ponderação; } \\
\text { (b) Contratação de } \\
\text { consultorias para } \\
\text { análise térmica e } \\
\text { acústica. }\end{array}$ & $\begin{array}{l}\text { (a) Realização da análise } \\
\text { de riscos; (b) } \\
\text { Mapeamento acústico } \\
\text { do entorno da obra. }\end{array}$ \\
\hline & Entraves & $\begin{array}{l}\text { (a) Escassez de profissionais } \\
\text { habilitados para realizar as } \\
\text { análises de risco; (b) Aumento } \\
\text { de custos para contratar } \\
\text { profissionais e realizar ensaios } \\
\text { relacionados às análises de } \\
\text { riscos. }\end{array}$ & $\begin{array}{l}\text { Não foram } \\
\text { identificados. }\end{array}$ & $\begin{array}{l}\text { (a) Aumento de } \\
\text { custos para } \\
\text { contratar } \\
\text { profissionais e } \\
\text { realizar ensaios } \\
\text { relacionados às } \\
\text { análises de riscos; } \\
\text { (b) Despreparo dos } \\
\text { projetistas para } \\
\text { elaborar análises de } \\
\text { riscos. } \\
\end{array}$ & $\begin{array}{l}\text { (a) Aumento de custos } \\
\text { para contratar } \\
\text { profissionais e realizar } \\
\text { ensaios relacionados às } \\
\text { análises de riscos. }\end{array}$ \\
\hline & Benefícios & $\begin{array}{c}\text { (a) Padronização e } \\
\text { ponderação da análise de } \\
\text { riscos; (b) Mitigação dos } \\
\text { riscos; (c) Proteção financeira; } \\
\text { (d) Promoção de escolhas } \\
\text { mais assertivas e adequadas } \\
\text { ao local de implementação da } \\
\text { obra. }\end{array}$ & $\begin{array}{l}\text { Não foram } \\
\text { identificados. }\end{array}$ & $\begin{array}{l}\text { (a) Segurança } \\
\text { jurídica decorrente } \\
\text { da verificação dos } \\
\text { riscos existentes à } \\
\text { época de projeto. }\end{array}$ & $\begin{array}{l}\text { (a) Investigação de } \\
\text { maior número de riscos } \\
\text { à época de projeto; (b) } \\
\text { Maior qualidade do } \\
\text { empreendimento. }\end{array}$ \\
\hline \multirow{3}{*}{ 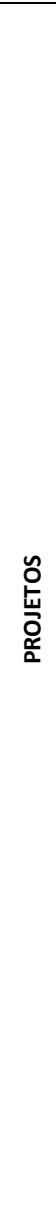 } & Mudanças & $\begin{array}{l}\text { (a) Contratação de novas } \\
\text { especialidades de projeto } \\
\text { (térmica, acústica e lumínica); } \\
\text { (b) Criação e atualização de } \\
\text { checklists de verificação de } \\
\text { projetos (acústica, térmica, } \\
\text { lumínica, instalações } \\
\text { hidráulicas, estruturas, } \\
\text { sistema de proteção de } \\
\text { descargas atmosféricas, } \\
\text { fachadas e } \\
\text { impermeabilização); (c) } \\
\text { Elaboração do PDE; } \\
\text { (d) Exigência em contrato do } \\
\text { atendimento à norma de } \\
\text { desempenho e especificações } \\
\text { de VUP e cuidados no uso e } \\
\text { manutenção; (e) Elaboração } \\
\text { de soluções padrão para } \\
\text { algumas disciplinas de projeto }\end{array}$ & $\begin{array}{l}\text { (a) Revisão do } \\
\text { PDE; (b) Exigência } \\
\text { em contrato do } \\
\text { atendimento à } \\
\text { NBR } 15575: 2013 \text { e } \\
\text { da especificação } \\
\text { em projeto da VUP } \\
\text { e das } \\
\text { recomendaçães ao } \\
\text { uso, operação e } \\
\text { manutenção dos } \\
\text { sistemas } \\
\text { projetados. }\end{array}$ & $\begin{array}{l}\text { (a) Adequação dos } \\
\text { checklists de } \\
\text { verificação de } \\
\text { projeto; (b) } \\
\text { Melhoria do PDE; } \\
\text { (c) Exigência em } \\
\text { contrato do } \\
\text { atendimento à NBR } \\
15575: 2013 ; \text { (d) } \\
\text { Modificação do } \\
\text { protocolo de } \\
\text { alterações de } \\
\text { projeto durante a } \\
\text { obra. }\end{array}$ & $\begin{array}{l}\text { (a) Criação de checklist } \\
\text { de projeto específico } \\
\text { para verificação das } \\
\text { exigências da norma de } \\
\text { desempenho; (b) } \\
\text { Criação do PDE; (c) } \\
\text { Adequação dos projetos } \\
\text { (especificação da VUP, } \\
\text { cuidados no uso, } \\
\text { operação e manutenção; } \\
\text { (d) Exigência em } \\
\text { contrato do } \\
\text { atendimento à NBR } \\
\text { 15575:2013; (e) Maior } \\
\text { detalhamento dos } \\
\text { memoriais descritivos. }\end{array}$ \\
\hline & Entraves & $\begin{array}{l}\text { (a) Variabilidade de custos e } \\
\text { soluções de projeto; (b) } \\
\text { Aumento de custos para } \\
\text { contratação de projetistas. }\end{array}$ & $\begin{array}{l}\text { Não foram } \\
\text { identificados. }\end{array}$ & $\begin{array}{l}\text { (a) Maior tempo } \\
\text { demandado para } \\
\text { verificação de } \\
\text { projetos. }\end{array}$ & $\begin{array}{c}\text { (a) Baixo nível de } \\
\text { detalhamento dos } \\
\text { projetos. }\end{array}$ \\
\hline & Benefícios & $\begin{array}{l}\text { (a) Redução de retrabalho; (b) } \\
\text { Maior registro e } \\
\text { documentação das } \\
\text { informações; (c) Maior } \\
\text { detalhamento dos memoriais } \\
\text { descritivos por meio da } \\
\text { especificação de normas } \\
\text { técnicas, VUP, consideraçães } \\
\text { acerca do uso, operação e } \\
\text { manutenção de sistemas e } \\
\text { definição do método de } \\
\text { avaliação de desempenho. }\end{array}$ & $\begin{array}{c}\text { (a) Maior } \\
\text { detalhamento dos } \\
\text { memoriais } \\
\text { descritivos, os } \\
\text { quais passaram a } \\
\text { indicar o } \\
\text { atendimento à } \\
\text { NBR 15575:2013 e } \\
\text { à outras normas } \\
\text { técnicas de caráter } \\
\text { prescritivo; (b) } \\
\text { Maior } \\
\text { atendimento às } \\
\text { normas técnicas. }\end{array}$ & $\begin{array}{l}\text { (a) Redução do } \\
\text { retrabalho durante } \\
\text { a execução dos } \\
\text { empreendimentos. }\end{array}$ & $\begin{array}{l}\text { (a) Maior qualidade dos } \\
\text { projetos }\end{array}$ \\
\hline
\end{tabular}

Quadro 3. Mudanças, entraves e benefícios, por processo, decorrentes da implementação da norma de desempenho (Continua)

Fonte: Elaborado pelos autores. 
Quadro 3. Mudanças, entraves e benefícios, por processo, decorrentes da implementação da norma de desempenho (Continuação)

Fonte: Elaborado pelos autores.

\begin{tabular}{|c|c|c|c|c|c|}
\hline \multicolumn{2}{|c|}{$\begin{array}{l}\text { EMPRESA } \\
\text { PROCESSO } \\
\end{array}$} & EMPRESA A & EMPRESA B & EMPRESA C & EMPRESA D \\
\hline \multirow{3}{*}{ 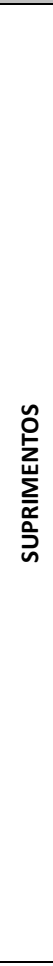 } & Mudanças & $\begin{array}{c}\text { (a) Aumento da } \\
\text { quantidade de } \\
\text { informações fornecidas } \\
\text { aos fabricantes; (b) } \\
\text { Aumento da quantidade } \\
\text { de informações fornecidas } \\
\text { pelos fornecedores; (c) } \\
\text { Solicitações de compra } \\
\text { feitas por desempenho, de } \\
\text { acordo com o PCT; (d) O } \\
\text { recebimento de materiais } \\
\text { passou a envolver a } \\
\text { participação dos } \\
\text { engenheiros de obra. }\end{array}$ & \multirow{3}{*}{$\begin{array}{l}\text { Por não ter iniciado a } \\
\text { execução de } \\
\text { empreendimentos } \\
\text { após a entrada em } \\
\text { vigor da norma de } \\
\text { desempenho, a } \\
\text { Empresa B não } \\
\text { realizou a compra de } \\
\text { materiais adequados } \\
\text { às exigências da } \\
\text { normativa bem } \\
\text { como não realizou } \\
\text { nenhuma ação para } \\
\text { adequação do } \\
\text { processo de } \\
\text { suprimentos. }\end{array}$} & $\begin{array}{l}\text { (a) Utilização das } \\
\text { especificações de } \\
\text { projeto e do PCT } \\
\text { para compra de } \\
\text { materiais;(b) } \\
\text { Criação de caderno } \\
\text { de especificação de } \\
\text { materiais; } \\
\text { (c)Participação do } \\
\text { corpo técnico na } \\
\text { avaliação dos } \\
\text { materiais recebidos; } \\
\text { (d) Solicitação de } \\
\text { laudos de } \\
\text { caracterização de } \\
\text { desempenho. }\end{array}$ & $\begin{array}{l}\text { (a) Adequação do } \\
\text { processo de aquisição; } \\
\text { (b) Criação do } \\
\text { documento “Caderno de } \\
\text { Especificações de } \\
\text { Materiais”; (c) } \\
\text { Adequação da } \\
\text { qualificação dos } \\
\text { fornecedores; (d) } \\
\text { Solicitação de laudos } \\
\text { comprobatórios de } \\
\text { desempenho aos } \\
\text { fornecedores. }\end{array}$ \\
\hline & Entraves & $\begin{array}{l}\text { (a) Aumento do prazo para } \\
\text { o fornecimento de } \\
\text { informações acerca do } \\
\text { desempenho dos materiais } \\
\text { por parte dos } \\
\text { fornecedores; (b) Escassez } \\
\text { de fornecedores } \\
\text { adequados às exigências } \\
\text { da norma de desempenho }\end{array}$ & & $\begin{array}{l}\text { (a) Despreparo dos } \\
\text { fornecedores para } \\
\text { caracterizar o } \\
\text { desempenho de } \\
\text { seus produtos; (b) } \\
\text { Custo de aquisição } \\
\text { de normas técnicas } \\
\text { prescritivas. }\end{array}$ & $\begin{array}{l}\text {-Não foram } \\
\text { identificados. }\end{array}$ \\
\hline & Benefícios & $\begin{array}{l}\text { (a) Maior qualidade dos } \\
\text { materiais adquiridos; (b) } \\
\text { Maior confiabilidade nos } \\
\text { fornecedores do mercado. }\end{array}$ & & $\begin{array}{c}\text { (a) Garantia da } \\
\text { qualidade dos } \\
\text { produtos adquiridos }\end{array}$ & $\begin{array}{l}\text { (a) Aquisições coerentes } \\
\text { com as necessidades dos } \\
\text { empreendimentos; } \\
\text { (b) Sobreposição da } \\
\text { qualidade aos custos. }\end{array}$ \\
\hline \multirow{3}{*}{ 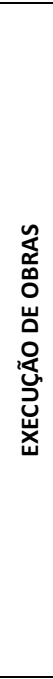 } & Mudanças & $\begin{array}{l}\text { (a) Elaboração do PCT; (b) } \\
\text { Obras passaram a solicitar } \\
\text { materiais de acordo com o } \\
\text { PCT; (c) Treinamentos com } \\
\text { as equipes de obras acerca } \\
\text { da importância da norma } \\
\text { de desempenho. }\end{array}$ & \multirow{3}{*}{$\begin{array}{l}\text { Por não ter iniciado a } \\
\text { execução de } \\
\text { empreendimentos } \\
\text { após a entrada em } \\
\text { vigor da norma de } \\
\text { desempenho, a } \\
\text { Empresa B não } \\
\text { realizou nenhuma } \\
\text { ação para adequação } \\
\text { de seu processo de } \\
\text { execução de obras. }\end{array}$} & $\begin{array}{l}\text { (a) Elaboração do } \\
\text { PCT; (b) } \\
\text { Treinamentos com } \\
\text { mestres e } \\
\text { encarregados } \\
\text { acerca da norma de } \\
\text { desempenho. }\end{array}$ & $\begin{array}{l}\text { (a) Elaboração do PCT; } \\
\text { (b) Maior quantidade de } \\
\text { registros e inspeções de } \\
\text { serviços; } \\
\text { (c) Treinamento da mão } \\
\text { de obra da mão de obra } \\
\text { acerca da norma de } \\
\text { desempenho. }\end{array}$ \\
\hline & Entraves & $\begin{array}{l}\text { (a) Aumento de custos } \\
\text { decorrente da necessidade } \\
\text { de realização dos ensaios } \\
\text { elencados no PCT. }\end{array}$ & & $\begin{array}{l}\text { (a) Soluções de } \\
\text { projeto que } \\
\text { atendam à norma } \\
\text { de desempenho } \\
\text { quanto à } \\
\text { propagação de } \\
\text { chamas em shafts. }\end{array}$ & $\begin{array}{l}\text { (a) Maior carga de } \\
\text { trabalho devido ao } \\
\text { maior número de } \\
\text { registros. }\end{array}$ \\
\hline & Benefícios & $\begin{array}{l}\text { (a) Sistematização de } \\
\text { informações acerca dos } \\
\text { ensaios a serem realizados } \\
\text { em cada obra oriunda da } \\
\text { elaboração do PCT. }\end{array}$ & & $\begin{array}{l}\text { (a) Confiança na } \\
\text { qualidade dos } \\
\text { materiais utilizados; } \\
\text { (b) Rigor no } \\
\text { controle da } \\
\text { execução. }\end{array}$ & $\begin{array}{l}\text { (a) Maior qualidade do } \\
\text { empreendimento; } \\
\text { (b) Redução de } \\
\text { retrabalhos. }\end{array}$ \\
\hline \multirow{3}{*}{ 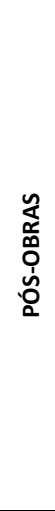 } & Mudanças & $\begin{array}{l}\text { (a) Atualização dos } \\
\text { manuais dos usuários com } \\
\text { inserção das garantias e } \\
\text { cuidados no uso, operação } \\
\text { e manutenção dos } \\
\text { empreendimentos. }\end{array}$ & $\begin{array}{l}\text { (a) Atualização dos } \\
\text { manuais dos } \\
\text { usuários com } \\
\text { inserção das } \\
\text { garantias e cuidados } \\
\text { no uso e operação. }\end{array}$ & $\begin{array}{l}\text { (a) Atualização dos } \\
\text { manuais dos } \\
\text { usuários com } \\
\text { indicação das } \\
\text { manutenções por } \\
\text { sistema e } \\
\text { caracterização dos } \\
\text { materiais por } \\
\text { desempenho. }\end{array}$ & $\begin{array}{l}\text { (a) Atualização dos } \\
\text { manuais dos usuários. }\end{array}$ \\
\hline & Entraves & $\begin{array}{l}\text { (a) Falta de informatização } \\
\text { dos manuais dos usuários. }\end{array}$ & $\begin{array}{c}\text { Não foram } \\
\text { identificados. }\end{array}$ & $\begin{array}{c}\text { Não foram } \\
\text { identificados. }\end{array}$ & Não foram identificados. \\
\hline & Benefícios & $\begin{array}{l}\text { (a) Proteção de cobranças } \\
\text { decorrentes do } \\
\text { inadequado uso e não } \\
\text { realização das } \\
\text { manutenções periódicas. }\end{array}$ & $\begin{array}{l}\text { Não foram } \\
\text { identificados. }\end{array}$ & $\begin{array}{l}\text { Não foram } \\
\text { identificados. }\end{array}$ & Não foram identificados. \\
\hline
\end{tabular}


A Planilha de Análise de Risco (Quadro 4) se apresentou como um documento importante para o conhecimento e registro das características do local de implantação do empreendimento. Embora não tenha sido usada para alimentar o processo de projeto em nenhuma das empresas investigadas, conforme dados coletados por meio das entrevistas e análise de documentos, a estruturação do processo de análise de riscos permitirá que, com o amadurecimento dos processos gerenciais de atendimento à NBR 15575:2013, essa análise possa ser incorporada como entrada de projetos e, mesmo antes, como ferramenta de análise da viabilidade do empreendimento. Por outro lado, o registro das condições atuais para implantação do empreendimento permite que as empresas se resguardem quanto a alterações futuras no entorno e nas condições do terreno, que não poderiam ser previstas à época dos projetos.

\begin{tabular}{|c|c|c|c|c|c|}
\hline \multirow{2}{*}{\multicolumn{2}{|c|}{$\begin{array}{l}\text { SETOR DE } \\
\text { COORDENAÇÃO DE } \\
\text { PROJETOS }\end{array}$}} & \multirow{2}{*}{\multicolumn{3}{|c|}{ CONSTRUTORA C }} & DATA: \\
\hline & & & & & REVISÃO: \\
\hline \multicolumn{6}{|c|}{ EM-151 - EDIFÍCIO X } \\
\hline \multirow{3}{*}{\multicolumn{2}{|c|}{$\begin{array}{l}\text { LEGENDA PARA } \\
\text { PREENCHIMENTO: }\end{array}$}} & 1 - BAIXO & \multicolumn{3}{|c|}{$\begin{array}{l}\text { Probabilidade: Possibilidade remota de } \\
\text { ocorrer, não existe evidência de registros }\end{array}$} \\
\hline & & 2 - INTERMEDIÁRIO & \multicolumn{3}{|c|}{$\begin{array}{l}\text { Probabilidade: Existe a evidência de } \\
\text { ocorrência, porém em um período superior a } \\
\text { um ano. }\end{array}$} \\
\hline & & 3 - SUPERIOR & \multicolumn{3}{|c|}{$\begin{array}{l}\text { Probabilidade: Existe a evidência de } \\
\text { ocorrência em período inferior a um ano. }\end{array}$} \\
\hline \multicolumn{6}{|c|}{ ANÁLISE DE RISCOS - IMPLANTAÇÃO DO EMPREENDIMENTO } \\
\hline \multirow[b]{2}{*}{ ITEM } & \multirow[b]{2}{*}{$\begin{array}{l}\text { DESCRIÇÃO } \\
\text { DO RISCO }\end{array}$} & \multicolumn{3}{|c|}{ ANÁLISE DE RISCOS } & \multirow[b]{2}{*}{$\begin{array}{l}\text { PLANO DE } \\
\text { AÇÃO }\end{array}$} \\
\hline & & $\begin{array}{l}\text { PROBABILIDADE DE } \\
\text { OCORRÊNCIA }\end{array}$ & IMPACTO & $\begin{array}{l}\text { NÍVEL DE RISCO } \\
\text { (PROBABILIDADE } \\
\text { x IMPACTO) } \\
\end{array}$ & \\
\hline 1 & $\begin{array}{l}\text { Enchentes } \\
\text { / sistema } \\
\text { de } \\
\text { drenagem } \\
\text { urbana } \\
\text { existente } \\
\end{array}$ & & & & \\
\hline 26 & $\begin{array}{c}\text { Danos } \\
\text { causados a } \\
\text { edificações } \\
\text { vizinhas }\end{array}$ & & & & \\
\hline \multicolumn{6}{|c|}{ RESPONSÁVEL PELA ANÁLISE: } \\
\hline \multicolumn{6}{|c|}{ FORM. 85/2-09/10/2017 } \\
\hline
\end{tabular}

No entanto, na percepção dos autores, os métodos de preenchimento deste documento são baseados em procedimentos empíricos e carecem de padronização e em alguns casos de respaldo técnico, já que por vezes não contou com o parecer de especialistas em mecânica de solos ou projeto de fundações, a título de exemplo. Um outro ponto que requer estudos são as métricas utilizadas para determinação da probabilidade de ocorrência de riscos, os quais apresentaram parâmetros de caracterização diferentes entre as empresas estudadas. Por fim, enfatiza-se que a Empresa $\mathrm{C}$ afirmou durante a realização da entrevista que a análise de risco não é alvo de cobranças técnicas ou jurídicas, o que evidencia a necessidade de fiscalização por parte do poder público em relação ao cumprimento desta atividade e suscita a necessidade da aplicação de penalizações em caso de descumprimento.
Quadro 4. Planilha de análise de riscos adotada pela Empresa C

Fonte: Arquivo da Empresa C 
A atualização dos checklists de projetos, decorrentes da inserção das novas exigências da norma de desempenho, é uma atividade que impulsiona a revisão das práticas das empresas e o atendimento às normas técnicas prescritivas. Neste sentido, cabe ressaltar as dificuldades de acesso às normatizações brasileiras citadas pelas empresas, diante dos custos de aquisição, realidade que atravanca a adequação técnica da indústria da construção e demanda mobilizações no sentido de facilitar o acesso às normativas.

Ainda em relação aos checklists de verificação de projetos, observou-se que, enquanto as Empresa A e C optaram por atualizar os checklists existentes nas empresas, a exemplo do checklist de verificação de projetos de acústica desenvolvido pela Empresa A (Quadro 5). A Empresa D optou por desenvolver um checklist exclusivo sobre a norma de desempenho, o qual se compila todas as especialidades de projetos. Essa dualidade de posicionamentos fomenta a necessidade de verificação da eficiência da utilização, em termos de otimização de tempo, das diferentes configurações de checklists.

Quadro 5. Checklist de verificação de projeto de acústica adotado pela Empresa A

Fonte: Arquivo da Empresa

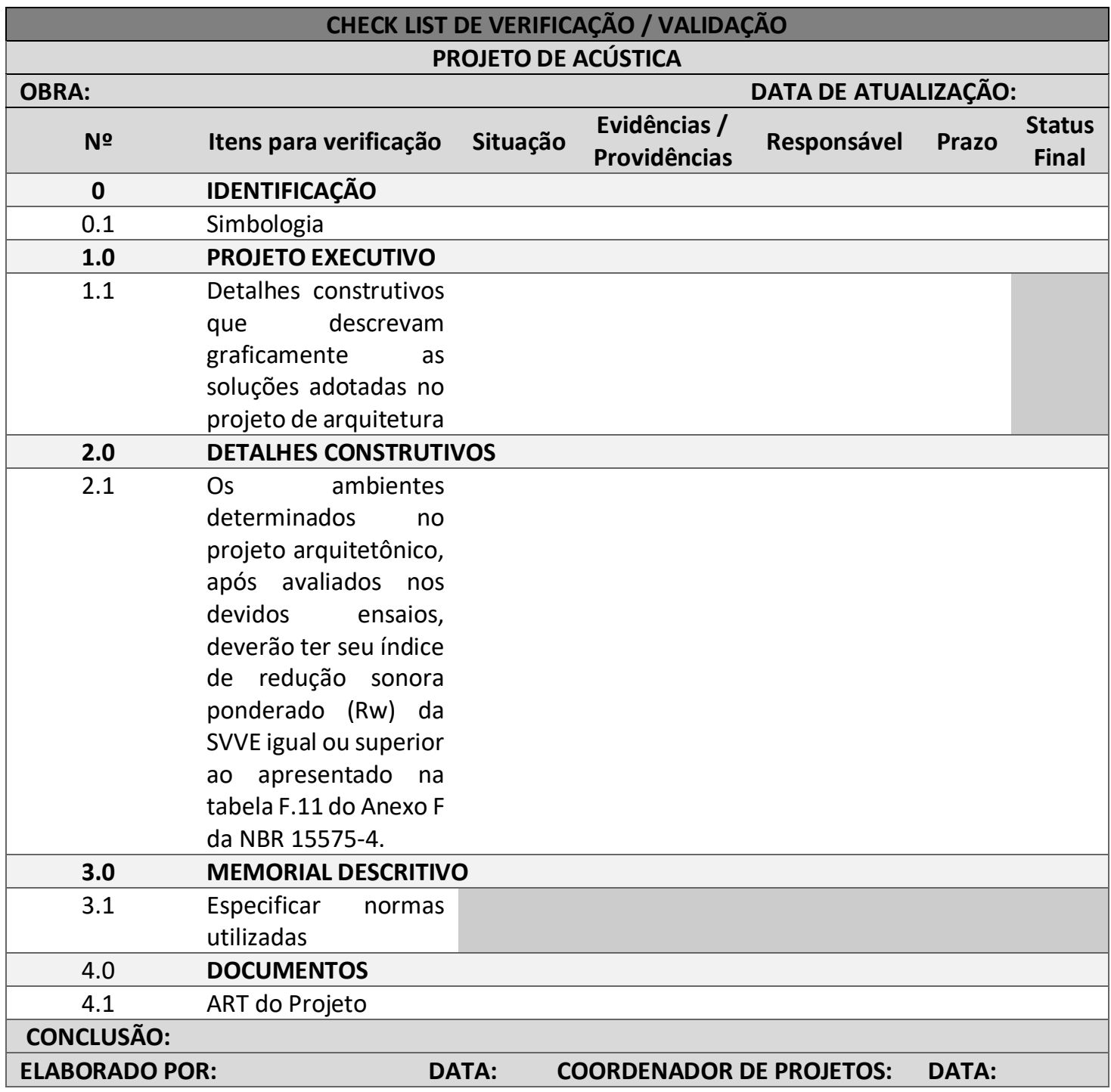


A introdução de checklists de projeto, ainda que de forma ainda incipiente, suscita algumas questões. Em primeiro lugar, até que ponto esses checklists servirão apenas para validação das soluções construtivas ou, usados em colaboração entre construtora e projetistas, poderão balizar o desenvolvimento e coordenação de projetos? Por outro lado, as empresas por enquanto estão "internalizando" essas atividades de verificação de projetos. Entende-se que, como fruto do amadurecimento gerencial das empresas com relação à NBR 15575:2013, a consolidação de parcerias com projetistas e consultores permitirá que o desenvolvimento e utilização desses checklists sejam compartilhados.

A exigência em contrato do atendimento à NBR 15575:2013 e da especificação da VUP e dos cuidados no uso, operação e manutenção bem como da necessidade de visitas periódicas dos projetistas às obras resguarda as empresas construtoras e incorporadas, mas, no entanto, não as exime da verificação das informações repassadas. Além disso, verificou-se que muitos projetistas ainda não têm ciência do que deve ser feito para adequar seus produtos à norma de desempenho, restando às empresas construtoras prover as informações necessárias a estes agentes, o que tem gerado insatisfação.

Observou-se que as empresas têm adequado seus protocolos internos de alteração de projetos durante a execução de obras de forma que as modificações só sejam realizadas mediante a anuência dos projetistas. Isto tem ganhado força devido à implementação da norma de desempenho, porém, cabe ressaltar que essa prática deveria ser mandatória, uma vez que os projetos são documentos que possuem responsabilidade técnica e cuja alteração indevida pode gerar punições legais.

Os documentos exigidos pelo regimento SiAC, por sua vez, necessitam de avaliações mais aprofundadas a fim de identificar sua validade e aplicação prática. Neste sentido, observou-se que o PDE (Quadro 6), foi preenchido por todas as empresas apenas com o nível mínimo de desempenho, que é de atendimento compulsório, e que a Empresa D informou que o documento é apenas interno à empresa, não sendo repassado aos projetistas, conforme exigência do SiAC. Mostram-se assim questionáveis as reais contribuições deste documento ao desempenho dos empreendimentos. Por outro lado, o PCT (Quadro 7) se mostrou eficaz para embasar a realização de ensaios em obra e as especificações de compra de materiais.

\begin{tabular}{|c|c|c|c|}
\hline \multicolumn{4}{|c|}{ PDE - PERFIL DE DESEMPENHO DA EDIFICAÇÃO } \\
\hline \multicolumn{4}{|l|}{ OBRA: } \\
\hline \multicolumn{3}{|c|}{ REQUISITO / EXIGÊNCIA DO USUÁRIO } & $\begin{array}{c}\text { NÍVEL DE } \\
\text { DESEMPENHO }\end{array}$ \\
\hline \multirow{5}{*}{$\begin{array}{l}\text { DESEMPENHO } \\
\text { TÉRMICO }\end{array}$} & \multirow{2}{*}{ SIMPLIFICADO } & COBERTURA & MÍNIMO \\
\hline & & SVVE & MíNIMO \\
\hline & \multirow{3}{*}{ SIMULAÇÃO } & Desempenho térmico no verão & MÍNIMO \\
\hline & & Desempenho térmico no inverno & MíNIMO \\
\hline & & Aberturas para ventilação & MÍNIMO \\
\hline
\end{tabular}

Quadro 6. Perfil de desempenho da edificação (PDE) adotado pela Empresa $A$

Fonte: Arquivo da Empresa $\mathrm{A}$ 
Quadro 7. Plano de controle tecnológico da obra (PCT) adotado pela Empresa D

Fonte: Arquivo da Empresa

\begin{tabular}{|c|c|c|c|c|c|c|c|c|}
\hline \multicolumn{4}{|c|}{ PCT - PLANO DE CONTROLE TECNOLÓGICO } & \multicolumn{2}{|c|}{ Versão: } & \multicolumn{2}{|c|}{$\begin{array}{c}\text { Data } \\
\text { elaboração: }\end{array}$} & \multirow[t]{2}{*}{ Obra: } \\
\hline \multirow[b]{2}{*}{$\begin{array}{c}\text { Componente/Elemento } \\
\text { ou Sistema }\end{array}$} & \multirow[b]{2}{*}{ Critério } & \multirow[b]{2}{*}{$\begin{array}{l}\text { Tipo de } \\
\text { Ensaio }\end{array}$} & \multirow[b]{2}{*}{ Frequência } & \multicolumn{4}{|c|}{ Responsável } & \\
\hline & & & & 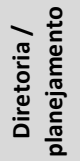 & $\frac{\text { ㄸํㅇ }}{0}$ & 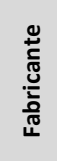 & 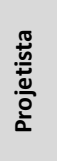 & $\begin{array}{l}\text { Acompanhamento das } \\
\text { ações e dados gerais }\end{array}$ \\
\hline \multicolumn{9}{|c|}{ OBRA } \\
\hline \multicolumn{9}{|c|}{ Estrutural } \\
\hline $\begin{array}{l}\text { Sistemas estruturais de } \\
\text { concreto }\end{array}$ & $\begin{array}{l}\text { Resistência } \\
\text { à } \\
\text { compressão }\end{array}$ & $\begin{array}{l}\text { Ensaio de } \\
\text { resistência à } \\
\text { compressão } \\
\text { de CP de } \\
\text { concreto }\end{array}$ & \begin{tabular}{|c|} 
A cada \\
caminhão \\
de concreto \\
entregue na \\
obra;
\end{tabular} & & $\mathrm{x}$ & & & \\
\hline \multicolumn{9}{|c|}{ Segurança no uso e operação } \\
\hline $\begin{array}{l}\text { Sistema de vedação } \\
\text { vertical interna e externa } \\
\text { - Esquadrias e fachadas } \\
\text { envidraçadas }\end{array}$ & $\begin{array}{l}\text { Controle } \\
\text { tecnológico } \\
\text { de } \\
\text { execução }\end{array}$ & $\begin{array}{c}\text { Ensaios de } \\
\text { esquadrias e } \\
\text { fachadas } \\
\text { envidraçadas } \\
\text { segundo a } \\
\text { NBR } \\
\text { 10821:2017. }\end{array}$ & $\begin{array}{c}\text { Durante a } \\
\text { execução } \\
\text { da fachada; }\end{array}$ & & $\mathbf{x}$ & & & \\
\hline \multicolumn{9}{|c|}{ Tátil e antropodinâmico } \\
\hline Sistema de piso & Planicidade & $\begin{array}{l}\text { Ensaio de } \\
\text { campo }\end{array}$ & $\begin{array}{c}\text { Término do } \\
\text { serviço. }\end{array}$ & & $\mathbf{x}$ & & & \\
\hline
\end{tabular}

Em relação ao processo de execução de obras, percebe-se que a implementação da norma de desempenho impulsiona a melhoria da qualidade dos serviços bem como o maior registro e documentação das informações. A produção de evidências da execução não só contribui para segurança jurídica das empresas como também permite a replicação de sistemas cujo desempenho se mostra adequado sem a necessidade de realização de novos ensaios.

Os Manuais de Uso, Operação e Manutenção também se tornaram mais técnicos e fornecem maior número de informações para auxiliar os usuários na execução das manutenções. Neste sentido, observou-se que as empresas passaram a inserir informações acerca dos prazos de garantia e desempenho de materiais, dos cuidados no uso, operação e manutenção e de indicações de manutenções por sistema.

Diante da relevância do processo de projetos para a adequada implementação da NBR 15575:2013, dada a maior quantidade de ações necessárias, bem como da forte sinergia deste processo com os demais, serão apresentadas soluções à implementação da norma de desempenho para o processo de projetos.

\section{SOLUÇÕES PARA O PROCESSO DE PROJETOS}

Com base no estudo de caso, em particular à percepção das dificuldades encontradas pelas empresas na implementação da NBR 15575:2013, foram esboçadas soluções para implementação, as quais não possuem caráter limitante, uma vez que estão relacionadas ao contexto das informações coletadas durante esta pesquisa.

Em relação especificamente ao processo de projetos, cabe aos gestores do processo de projetos entender quais informações, além da VUP, durabilidade e manutenibilidade dos sistemas; devem ser obrigatoriamente especificadas em projeto e exigir dos projetistas o adequado detalhamento destas bem como realizar a adequada verificação, quando do recebimento dos projetos. Isto se faz fundamental quer a empresa construtora elabore os projetos internamente 
ou contrate projetistas especializados para desenvolvê-los. 0 cumprimento independe de onde os projetos são realizados.

Estabelecido o que compete a cada especialidade de projeto, deve-se registrar formalmente tais exigências. No caso dos projetos elaborados pela própria empresa construtora, devem ser desenvolvidos documentos internos que formalizem as exigências a serem atendidas, os quais devem ser devidamente referendados e arquivados. No caso dos projetos contratados, essas exigências serão formalizadas por meio dos contratos. Neste caso, deve-se inserir adicionalmente uma cláusula genérica que exprima a necessidade de que as soluções adotadas pelos projetos estejam adequadas à NBR 15575:2013. Durante o processo de entendimento das exigências da NBR 15.755:2013, as empresas construtoras e os projetistas podem verificar ainda a necessidade de contratar novas especialidades de projeto, a exemplo das consultorias de térmica, acústica e lumínica.

Definidas e informadas formalmente aos projetistas as exigências que devem ser detalhadas em projetos, a verificação destes documentos, quando do recebimento, é também uma etapa crucial para garantir que as solicitações foram de fato consideradas e assegurar o alcance adequado de desempenho da edificação neste processo. Neste âmbito, os checklists de verificação são documentos que devem ser atualizados e passar a incluir as exigências da NBR 15575:2013. A forma como as exigências são especificadas nos checklists de verificação é particular à cada empresa, pode ser elaborado um único checklist que compile todas as exigências da norma de desempenho ou inserido, por especialidade de projeto, em cada checklist específico, às exigências relativas à norma de desempenho. Diante das experiências coletadas por meio dos estudos de casos, a segunda opção se mostra de maior eficiência, uma vez que facilita a verificação.

Ainda que não seja uma exigência oriunda da NBR 15575:2013, a compatibilização das diferentes especialidades de projeto também se faz necessária para garantia do adequado desempenho dos empreendimentos. As visitas dos projetistas às obras também devem se tornar prática e passar a ser exigência das contratações.

A elaboração do PDE é uma atividade pertinente para as empresas construtoras que fazem parte do PBQP-H. No entanto, as empresas devem suscitar o debate dentro da indústria da construção acerca da pertinência do documento e, de fato, repassá-lo aos projetistas como um dos documentos de entrada de projeto, como ressaltado anteriormente. Porém, critica-se a relevância da elaboração deste documento para empreendimentos onde todos os sistemas atenderão ao nível mínimo de desempenho.

\section{CONSIDERAÇÕES FINAIS}

Corroborando com o que fora estabelecido na revisão da literatura, os resultados coletados nesta pesquisa demonstram que as empresas construtoras e incorporadoras investigadas buscam implementar a NBR 15575:2013 desde 2013, mas sentem dificuldades para consolidar a implementação. Neste contexto, cabe destacar que esta pesquisa, ainda que aponte um panorama da cidade do Recife, tem seu universo baseado em um número pequeno de empresas, o que releva a necessidade de cautela na interpretação dos dados obtidos.

A identificação das principais atividades desenvolvidas para implementação permitiu, por conseguinte, que fossem estabelecidas soluções à implementação, resguardada a especificidade dos casos investigados, de forma que a pesquisa possui relevância técnica ao contribuir para nortear às empresas construtoras e incorporadoras na organização de suas atividades a fim de atender às exigências da NBR 15575:2013. 
Ressalta-se diante dos casos investigados, a importância do regimento SiAC do PBQP-H na mobilização de toda cadeia da construção civil para adequação à norma de desempenho. No entanto, falta ao setor entender a pertinência e aplicação prática dos documentos exigidos pelo regimento, PDE e PCT, uma vez que, até o momento, estes documentos estão sendo particularmente produzidos com intuito maior de viabilizar a certificação no programa.

Outrossim, foi identificado por meio dos estudos de casos que a implementação da norma de desempenho impulsiona o cumprimento das normas prescritivas bem como promove a revisão das práticas das empresas e está diretamente relacionada às tendências de sustentabilidade e otimização de recursos. Além disso, o maior entendimento das condições de uso e exposição, decorrente do desenvolvimento de análises do entorno da obra, para embasar o desenvolvimento de projetos reduz os riscos de falhas e, consequentemente, de responsabilizações judiciais. Porém, falta aos intervenientes da indústria da construção, trabalhar na divulgação do atendimento à NBR 15575:2013 como ferramenta de marketing e assim conseguir justificar os possíveis aumentos de custo decorrentes da normativa. Além de entender e assumir o compromisso social e técnico decorrente do seu atendimento.

Por fim, acredita-se que o presente trabalho contribuiu para o avanço científico do tema "implementação da NBR 15575" na medida em que ampliou o conhecimento sobre aspectos técnico-gerenciais associados à essa implementação.

\section{Referências Bibliográficas}

ASSOCIAÇÃO BRASILEIRA DE NORMAS TÉCNICAS - ABNT. NBR 15575: Edifícios habitacionais Desempenho. Rio de Janeiro, 2013.

ADAMY, A. P. A.; ROSA, F. S.; ROSA, L. C. Desempenho térmico de compósitos à base de talos de girassol em componentes de edificações. Revista Espacios, Caracas, v. 37, n. 15, p. 17. 2016. DOI: https://doi.org/10.1590/\$1983-41952015000300008

ANDERY, P., BARBOSA, P. Estudo sobre o Impacto do SIAC - Sistema de Avaliação da Conformidade - na Implementação da NBR 15.575:2013 em Empresas Construtoras. In: ENCONTRO NACIONAL DE TECNOLOGIA DO AMBIENTE CONSTRUÍDO, 17., 2018, Foz do Iguaçu. Anais... Porto Alegre: ANTAC, 2018.

BELÉM, K.; STARLING, C.; ANDERY, P. Impactos e desafios associados com a implantação da norma de desempenho em edificações prediais. In: ENCONTRO NACIONAL DE TECNOLOGIA DO AMBIENTE CONSTRUÍDO, 17., 2018, Foz do Iguaçu. Anais... Porto Alegre: ANTAC, 2018.

BOGO; A. J. Reflexões críticas quanto as limitações do texto das normas brasileiras de desempenho NBR 15220-3 e NBR 15575. HOLOS, Natal, v. 7, p. 290 -298. 2016. DOI: https://doi.org/10.15628/holos.2016.4389

BOLINA, F.; CHRIST, R.; METZLER, A.; QUININO, U.; TUTIKIAN, B. Comparison of the fire resistance of two structural wall systems in Light Steel Framing. DYNA, Bogotá, v. 84, n. 201, p. 123-128. 2017. DOI: http://dx.doi.org/10.15446/dyna.v84n201.57487

BOLINA, F. L.; PRAGER, G. L.; RODRIGUES, E.; TUTIKIAN, B. F. Avaliação da resistência ao fogo de paredes maciças de concreto armado. Ambiente Construído, Porto Alegre, v. 15, n. 4, p. 291-305, out./dez. 2015. DOI: https://doi.org/10.1590/s1678-86212015000400051

BOLINA, F.; TUTIKIAN, B. Especificação frente à durabilidade para atender nível superior de desempenho em elementos estruturais enterrados. Revista IBRACON de Estruturas e Materiais, São Leopoldo, v. 9, n. 2, p. 275-296. 2016. DOI: https://doi.org/10.1590/S1983-41952016000200008 
BRASIL. Ministério de Estado das Cidades. Portaria n.o 383, de 14 de junho de 2018. Dispõe sobre o sistema de Avaliação da Conformidade de Empresas de Serviços e Obras da Construção Civil - SiAC. Disponível em < http://pbqp-h.cidades.gov.br/projetos siac.php>. Acesso em 12 Jul. 2018.

CENTRO DE TECNOLOGIA DE EDIFICAÇÕES (CTE). Norma de desempenho: Panorama atual e desafios futuros. São Paulo: CTE, 2016.

CHVATAL, K. M. S. Avaliação do procedimento simplificado da NBR 15575 para determinação do nível de desempenho térmico de habitações. Ambiente Construído, Porto Alegre, v. 14, n. 4, p. 119-134, out./dez. 2014. DOI: https://doi.org/10.1590/S1678-86212014000400009

COSTA, C. H. de A.; ILHA, M. S. de O. Componentes BIM de sistemas prediais hidráulicos e sanitários baseados em critérios de desempenho. Ambiente Construído, Porto Alegre, v. 17, n. 2, p. 157-174, abr./jun. 2017. DOI: https://doi.org/10.1590/s1678-86212017000200151

COTTA, A. C. Contribuição ao estudo dos impactos da NBR 15575:2013 no processo de gestão de projetos em empresas construtoras de pequeno e médio porte. 2017. 214 f. Dissertação (Mestrado) - Universidade Federal de Minas Gerais, Belo Horizonte, 2017.

COTTA, A. C.; ANDERY, P. R. P. A Norma de desempenho e as alterações no processo de projeto das empresas construtoras de pequeno e médio porte. In: ENCONTRO NACIONAL DE TECNOLOGIA DO AMBIENTE CONSTRUÍDO, 16., 2016, São Paulo. Anais... Porto Alegre: ANTAC, 2016.

COTTA, A. C.; ANDERY, P. R. P. As alterações no processo de projeto das empresas construtoras e incorporadoras devido à NBR 15575 - Norma de desempenho. Ambiente Construído, Porto Alegre, v. 18, n. 1, p. 133-152, jan./mar. 2018. DOI: https://doi.org/10.1590/s1678-86212018000100213

CRUSIUS, A. D. Metodologia para implantação da norma ABNT NBR 15575/2013 - Desempenho de Edificações Habitacionais - nas empresas da construção civil e de projeto arquitetônico com foco no mercado imobiliário. Revista Especialize, Goiânia, v.1, n.10, p. 1 -18, dez. 2015.

DALBEM, R.; CUNHA, E. G.; VICENTE, R.; FIGUEIREDO, A.; OLIVEIRA, R.; SILVA, A. C. S. B. Optimisation of a social housing for south of Brazil: From basic performance standard to passive house concept. Energy, Amsterdam, v. 167, n. 15, p. 1278-1296. 2019. DOl: https://doi.org/10.1016/i.energy.2018.11.053

FERREIRA, C. C.; SOUZA, H. A. de; ASSIS, E. S. de. Discussão dos limites das propriedades térmicas dos fechamentos opacos segundo as normas de desempenho térmico brasileiras. Ambiente Construído, Porto Alegre, v. 17, n. 1, p. 183- 200, jan./mar. 2017. DOI: https://doi.org/10.1590/s1678$\underline{86212017000100131}$

FOLIENTE, G. C. Stakeholder engagement in the performance approach - the Australian and European performance based building networks. In: CLIENTS DRIVING INNOVATION CONFERENCE, 2004, Austrália. Proceedings... Gold Coast, Austrália, 2004.

GALVÃO, T. F.; PANSANI, T. DE S. A.; HARRAD, D. Principais itens para relatar Revisões sistemáticas e Meta-análises: A recomendação PRISMA. Epidemiologia e Serviços de Saúde, v. 24, n. 2, p. 335-342, jun. 2015. DOI: https://doi.org/10.5123/S1679-49742015000200017

GARCEZ, M. R.; ROHDEN, A. B.; GODOY, L. G. G. The role of concrete compressive strength on the service life and life cycle of a RC structure: Case study. Journal of Cleaner Production, Amsterdam, $v$. 172, n. 20, p. 27-38. 2018. DOI: https://doi.org/10.1016/i.jclepro.2017.10.153

GARLET, L.; SOARES, R. M. D.; RUVIARO, R. S.; GODOY, J.; SANTOS, J. C. P. Impacto nos custos de composição de paredes estruturais para adequação aos critérios de desempenhos térmico e acústico 
da norma ABNT NBR 15575:2013. Ciência \& Engenharia, Uberlândia, v. 26, n. 2, p. 49-57. 2017. DOI: https://doi.org/10.14393/19834071.v26.n2.2017.39104

GIL, A. C. Como elaborar projetos de pesquisa. 4. ed. São Paulo: Atlas, 2002.

GIORGI, P.; GRIGOLETTI, G. C.; LIMA, R. C. A.; LORENZI, L. S. Avaliação de sustentabilidade e habitabilidade de blocos de solo-cimento segundo a norma ABNT NBR 15575. Matéria, Rio de Janeiro, v. 23, n. 3. 2018. DOI: http://dx.doi.org/10.1590/s1517-707620180003.0511

GUIDI, C. R.; ABRAHÃO, K. C. de F. J.; VELOSO, A. C. O.; SOUZA, R. V. G. de. Influência dos parâmetros urbanísticos e da topografia na admissão da luz natural em edifícios residenciais. Ambiente Construído, Porto Alegre, v. 18, n. 3, p. 49-66, jul./set. 2018. DOI: http://dx.doi.org/10.1590/s167886212018000300267

HENNEMANN, G. G.; GIL, A. M.; FERNANDES, B.; BOLINA, F. L.; TUTIKIAN, B. F. Avaliação teóricoexperimental da influência da espessura de alvenaria na resistência ao fogo de sistemas verticais de vedação. Ambiente Construído, Porto Alegre, v. 17, n. 4, p. 183-195, out./dez. 2017. DOI: https://doi.org/10.1590/s1678-86212017000400192.

KLIPPEL FILHO, S.; PRAGER, G. L.; SILVA, P. E. M., BOLINA, F. L.; TUTIKIAN, B. F. Comparative study of fire resistance and acoustic performance of ceramic brick walls in concern to NBR 15575 in residential buildings in Brazil. DYNA, Bogotá, v. 85, n. 204, p. 53-58. 2018. DOI: http://dx.doi.org/10.15446/dyna.v85n204.65586

MARCONI, M. A.; LAKATOS, E. M. Fundamentos de metodologia científica. 5. ed. São Paulo: Atlas, 2003.

MEIRA, A., VASQUE, S. Norma de desempenho: sua implantação junto a projetistas da cidade de João Pessoa. In: ENCONTRO NACIONAL DE TECNOLOGIA DO AMBIENTE CONSTRUÍDO, 17., 2018, Foz do Iguaçu. Anais... Porto Alegre: ANTAC, 2018.

MOURA, J. M. B. M.; SANTOS, J. T.; PINHEIRO, I. G. Percepção do impacto da NBR 15575 na sustentabilidade da edificação. Revista de Gestão Social e Ambiental, São Paulo, v. 10, n. 1, p. 72 92, jan./abr. 2016. DOI: https://doi.org/10.24857/rgsa.v10i1.1107

MORAIS, G.; LIRA, V.; PEREIRA, A.; NASCIMENTO, E.; LORDSLEEM JR., A.; MELHADO, S. O desempenho acústico e as empresas de projeto de arquitetura à luz da Norma de desempenho. In: ENCONTRO NACIONAL DE TECNOLOGIA DO AMBIENTE CONSTRUÍDO, 17., 2018, Foz do Iguaçu. Anais... Porto Alegre: ANTAC, 2018a.

MORAIS, G. A. T.; ABREU, M. M.; LORDSLEEM JR., A. C.; BARKOKÉBAS, B. Safety in the use and operation of residential buildings: evaluation according to the brazilian standard NBR 15575. In: Joint CIB W099 and TG59 International Safety, Health, and People in Construction Conference, 27., 2018, Salvador. Proceedings... Salvador: Marketing Aumentado, 2018b.

MORASSI, S. A.; SILVA, J. L. R.; ORTENZI, A. Comparative result between standard requirements and finite element analysis of wood-frame panels. Journal of Building Engineering, Amsterdam, v. 15, p. 78-84. 2018. DOI: https://doi.org/10.1016/j.jobe.2017.11.002

MOURA, J. M. B. M.; SANTOS, J. T.; PINHEIRO, I. G. Percepção do impacto da NBR 15575 na sustentabilidade da edificação. Revista de Gestão Social e Ambiental, São Paulo, v. 10, n. 1, p. 72 92, jan./abr. 2016. DOI: https://doi.org/10.24857/rgsa.v10i1.1107

MUNIZ-GÄAL, L. P.; PEZZUTO, C. C.; CARVALHO, M. F. H. de; MOTA, L. T. M. Eficiência térmica de materiais de cobertura. Ambiente Construído, Porto Alegre, v. 18, n. 1, p. 503-518, jan./mar. 2018. DOI: https://doi.org/10.1590/s1678-86212018000100235 
NOGUEIRA, J. R. da S.; CALLEJAS, I. J. A.; DURANTE, L. C. Desempenho de painel de vedação vertical externa em Light Steel Framing composto por placas de madeira mineralizada. Ambiente Construído, Porto Alegre, v. 18, n. 3, p. 289-307, jul./set. 2018. DOI: https://doi.org/10.1590/s1678$\underline{86212018000300282}$

OKAMOTO, P. S. Os impactos da norma brasileira de desempenho sobre o processo de projeto de edificações residenciais. 2015. 160 f. Dissertação (Mestrado) - Escola Politécnica da Universidade de São Paulo, São Paulo, 2015.

OKAMOTO, P. S.; MELHADO, S. B. A norma brasileira de desempenho e o processo de projeto de empreendimentos residenciais. In: ENCONTRO NACIONAL DE TECNOLOGIA DO AMBIENTE CONSTRUÍDO, 15., 2014, Maceió. Anais... Porto Alegre: ANTAC, 2014.

OLIVEIRA, L. A.; FONTENELLE, J. H.; MITIDIERI FILHO, C. V. Durabilidade de fachadas: método de ensaio para verificação da resistência à ação de calor e choque térmico. Ambiente Construído, Porto Alegre, v. 14, n. 4, p. 53-67, out./dez. 2014. DOI: https://doi.org/10.1590/S1678$\underline{86212014000400005}$

OLIVEIRA FILHO, M. V. M.; ZANNIN, P. H. T. Performance of Sound Insulation in Buildings - A Case Study. International Journal of Acoustics and Vibration, Auburn, v. 21, n. 3, p. 339 - 345. 2016. DOI: http://dx.doi.org/10.20855/ijav.2016.21.3429

OTERO, J. A.; SPOSTO, R. M. Caracterização da atuação de construtoras e incorporadoras de GoiâniaGO frente às normas de desempenho ABNT NBR 15575:2013. In: ENCONTRO NACIONAL DE TECNOLOGIA DO AMBIENTE CONSTRUÍDO, 16., 2016, São Paulo. Anais... Porto Alegre: ANTAC, 2016.

PACHECO, F.; KRUMENAUER, M.; MEDEIROS, D. R.; OLIVEIRA, M. F.; TUTIKIAN, B. F. Development of lightweight concrete subfloor with ethylene vinyl acetate (EVA) aggregates waste to reduce impact sound in flooring system. DYNA, Bogotá, v. 84, n. 201, p. 290-295. 2017. DOI: http://dx.doi.org/10.15446/dyna.v84n201.61491

PRANGE, E. M., LYRA, R. A., SANTOS, R. B. P. Os desafios da adequação do sistema de gestão de qualidade do PBQP-H à NBR 15.575:2013 na perspectiva dos auditores externos. In: ENCONTRO NACIONAL DE TECNOLOGIA DO AMBIENTE CONSTRUÍDO, 17., 2018, Foz do Iguaçu. Anais... Porto Alegre: ANTAC, 2018.

REUS NETTO, G.; CZAJKOWSKI, J. D. Comparación entre las normas de desempeño térmico edilício de Argentina y Brasil. Ambiente Construído, Porto Alegre, v. 16, n. 1, p. 105-122, jan./mar. 2016. DOI: https://doi.org/10.1590/s1678-86212016000100063

RIBEIRO, W. B.; RIZZO, M. V.; BORTOLUZ, N.; ZENI, M.; NUNES, M. F. O.; GRISA, A. M. C. Characterization of polyurethan skin agglomerates for acoustic insulation from impact noise. Materials Research, São Carlos, v. 17, supl. 1, p. 210-215, ago. 2014. DOI: https://doi.org/10.1590/1516-1439.226513

SANTANA, W. B.; MAUÉS, L. M. F.; SOEIRO, N. S.; PICANÇO, M. S. Rating of acoustic performance levels of NBR 15575 (2013) based on user perception: A case study in the Brazilian Amazon. Building Acoustics, Rome, v. 24, n.4, p. 239-254. 2017. DOI: https://doi.org/10.1177/1351010X17738107

SANTOS, J. C. P.; KOTHE, K. K.; MOHAMAD, G. VAGHETTI, M. A. O.; RIZZATTI, E. Comportamento térmico de fechamentos em alvenaria estrutural para a Zona Bioclimática 2 brasileira. Matéria, Rio de Janeiro, v.20, n.4, p.1030-1047. 2015. DOI: https://doi.org/10.1590/S1517-707620150004.0106

SANTOS, D. G.; CARVAlho, P. M.; CARVAlHO, E. M. de; FERREIRA, L. I. de M.; VIANA, M. R. Desempenho de edificações residenciais: projetistas e empresas construtoras. In: ENCONTRO 
NACIONAL DE TECNOLOGIA DO AMBIENTE CONSTRUÍDO, 16., 2016, São Paulo. Anais... Porto Alegre: ANTAC, 2016.

SANTOS, P. R. R. Investigação da adaptação organizacional de Construtoras de Aracaju à implantação da norma de desempenho. 2018. 147f. Dissertação (Mestrado) -Programa de Pós-Graduação em Engenharia Civil. Universidade Federal de Sergipe, São Cristóvão, 2018.

SANTOS, P. R. R.; SANTOS, D.G. Adaptações organizacionais estimuladas pela norma de desempenho nas construtoras brasileiras. In: ENCONTRO NACIONAL DE TECNOLOGIA DO AMBIENTE CONSTRUÍDO, 17., 2018, Foz do Iguaçu. Anais... Porto Alegre: ANTAC, 2018a.

SANTOS, P. R. R.; SANTOS, D.G. Investigação das mudanças realizadas por construtoras para adaptação à norma de desempenho na concepção de empreendimentos. In: ENCONTRO NACIONAL DE TECNOLOGIA DO AMBIENTE CONSTRUÍDO, 17., 2018, Foz do Iguaçu. Anais... Porto Alegre: ANTAC, 2018.

SARVEZUK, L. C.; SILVA, J. R. R. Adaptações nas metodologias projetuais das empresas de construção civil de Maringá oriundas da implementação da nova Norma de desempenho de edificações habitacionais - NBR 15575/2013. In: ENCONTRO NACIONAL DE PRODUÇÃO CIENTíFICA UNICESUMAR, 9., 2015, Maringá. Anais... Maringá: UniCesumar, 2015.

SCHVARSTZHAUPT, C. C.; TUTIKIAN, B. F.; NUNES, M. F. de O. Análise comparativa do desempenho acústico de Sistemas de fachada com esquadrias de PVC com persiana e diferentes tipos de de vidros em ensaios de laboratório. Ambiente Construído, Porto Alegre, v. 14, n. 4, p. 135-145, out./dez. 2014.

SENTENA, J. A. A.; KAZMIERCZAK, C. de S.; KREIN, L. A. Degradação de revestimentos de argamassa com finos de resíduos de concreto por ciclos térmicos. Ambiente Construído, Porto Alegre, v. 18, n. 1, p. 211-224, jan./mar. 2018. DOI: https://doi.org/10.1590/s1678-86212018000100217

SILVA, A. S.; GHISI, E. Análise comparativa dos resultados do desempenho térmico da envoltória de uma edificação residencial pelos métodos de simulação do RTQ-R e da NBR 15575-1. Ambiente Construído, Porto Alegre, v. 14, n. 1, p. 213-230, jan./mar. 2014.

SILVA, A. S.; SORGATO, M. J.; MAZZAFERRO, L.; MELO, A. P.; GHISI, E. Incerteza do método de simulação da NBR 15575- 1 para a avaliação do desempenho térmico de habitações. Ambiente Construído, Porto Alegre, v. 14, n. 4, p. 103-117, out./dez. 2014. DOI: https://doi.org/10.1590/S1678-86212014000400008

SILVA, A. T.; KERN, A. P.; PICCOLI, R.; GONZÁLEZ, M. A. S. Novas exigências decorrentes de programas de certificação ambiental de prédios e de normas de desempenho na construção. Arquiteturarevista, São Leopoldo, v. 10, n. 2, p. 105-114, jul./dez. 2014.

SILVA, E. J.; VELASCO, F. G.; LUZARDO, F. M.; MARQUES, M. L.; MILIAN, F. M.; RODRIGUES, L. B. Compósito cimentício com elevado teor de fibra de coco tratada: propriedades físicas e durabilidade. Matéria, Rio de Janeiro, v. 23, n. 3. 2018. DOI: https://doi.org/10.1590/s1517-707620180003.0499

SILVA, L. F. B. da; THOMAZ, E.; OLIVEIRA, L. A. de. Ventilated cladding systems: structural and drainability performance criteria. Ambiente Construído, Porto Alegre, v. 18, n. 3, p. 341-358, jul./set. 2018. DOI: https://doi.org/10.1590/s1678-86212018000300285

SOARES, M. M.; SILVA, A. C. S. B. da. Análise e compatibilização dos métodos simplificado e por simulação da NBR 15575: zona bioclimática 2. Ambiente Construído, Porto Alegre, v. 17, n. 1, p. $305-$ 327, jan./mar. 2017. DOI: https://doi.org/10.1590/s1678-86212017000100137 
SORGATO, M. J.; MELO, A. P.; MARINOSKI, D. L.; LAMBERTS, R. Análise do procedimento de simulação da NBR 15575 Para avaliação do desempenho térmico de edificações residenciais. Ambiente Construído, Porto Alegre, v. 14, n. 4, p. 83-101, out./dez. 2014. DOI: https://doi.org/10.1590/S1678$\underline{86212014000400007}$

TRIANA, M. A.; LAMBERTS, R.; SASSI, P. Characterization of representative building typologies for social housing projects in Brazil and its energy performance. Energy Policy, Amsterdam, v. 87, p. 524541. 2015. DOI: https://doi.org/10.1016/i.enpol.2015.08.041

TUBELO, R. C. S.; RODRIGUES, L. T.; GILLOTT, M. A. Comparative Study of the Brazilian Energy Labelling System and the Passivhaus Standard for Housing. Buildings, Basel, v. 4, p. 207-221. 2014.

TUBELO, R; RODRIGUES, L.; GILLOTT, M.; SOARES, J. C. G. Cost-effective envelope optimisation for social housing in Brazil's moderate climates zones. Building and Environment, Indiana, v. 133, p. 213 - 227. 2018. DOI: https://doi.org/10.1016/i.buildenv.2018.01.038

TUTIKIAN, B. F.; ZUCHETTO, L. K.; SOUZA, R. P. de; OLIVEIRA, M. F. de. Uso de agregado leve de EVA em contrapiso argamassado para isolamento ao ruído de impacto em edificações residenciais. Ambiente Construído, Porto Alegre, v. 17, n. 3, p. 295-306, jul./set. 2017. DOI: https://doi.org/10.1590/s1678-86212017000300177

VIANA, M. R., SANTOS, P. R. R., MICHELAN, D. C. G. S., SANTOS, D. G. Aplicabilidade da norma de desempenho em habitação popular: estudo de caso. In: ENCONTRO NACIONAL DE TECNOLOGIA DO AMBIENTE CONSTRUíDO, 17., 2018, Foz do Iguaçu. Anais... Porto Alegre: ANTAC, 2018.

WEBER, M. S. C.; JOPPERT, M. P. Redesenho estratégico de um programa federal com base em resultados de avaliação: o caso do Programa Brasileiro da Qualidade e Produtividade do Habitat PBQP-H. In: CONGRESSO CONSAD DE GESTÃO PÚBLICA, 4., 2011, Brasília, Anais... Brasília, 2011.
Gabriela Alves T. de Morais

gabriela_morais@outlool.com

Alberto Casado Lordsleem Jr. acasado@poli.br

Paulo Roberto Pereira Andery paulo@demc.ufmg.br 